\title{
Lust auf einen Platz auf unserem Cover?
}

Auf das Cover einer Zeitschrift schafft man es meist nur, wenn man reich, berühmt oder berüchtigt ist - oder aber ein junger Zahnarzt/eine junge Zahnärtzin! Schicken Sie uns Ihr Foto - und mit etwas Glück werden Sie ein Covermodel!

Cicher ist das nicht jedermanns Sache - und doch war die OResonanz beim vergangenen Aufruf, sich an der Covermodelwahl für das nächste Jahr zu beteiligen, sehr groß. So groß, dass eine schwere Auswahl getroffen und einige Absageschreiben verfasst werden mussten. Für alle, die immer noch oder erstmals Lust haben, eines unserer vier Covermodel für 2016 zu werden, gibt es eine neue Chance: Schi- cken Sie uns bis zum 31.12.2015 ein aktuelles Foto, Kontaktdaten und ein paar Zeilen über sich und ihr Leben als (angehender) Zahnarzt. Und wer weiß: Vielleicht läuft es dann bei Ihnen ja andersrum: Erst das Cover, dann reich, berühmt oder brüchtigt ...

Wir freuen uns auf Ihre Mail!
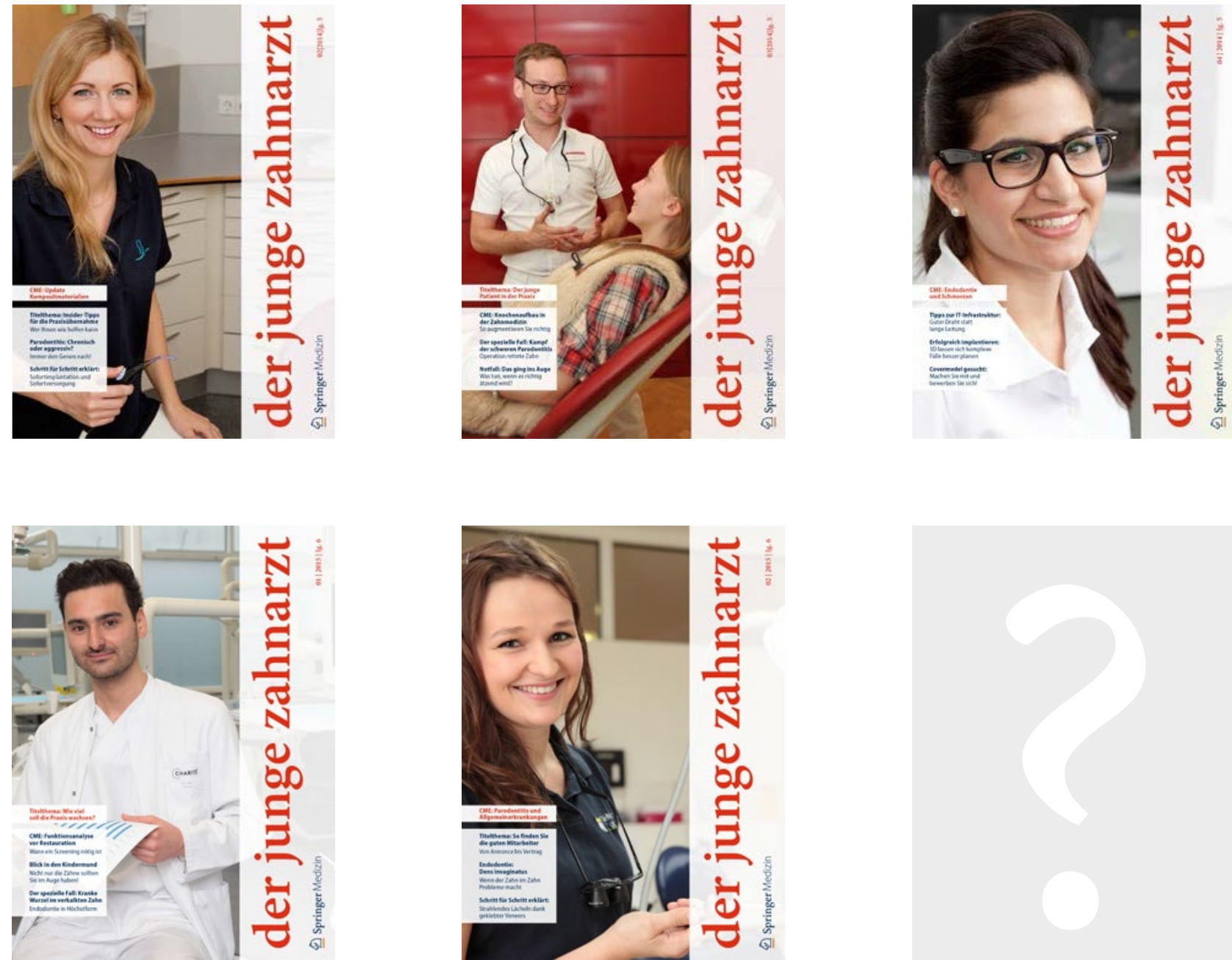

Schicken Sie Ihr Foto per Mail an: swanett.koops@springer.com. Einsendeschluss ist der 31.12.2015. 